\title{
Short-Term and Mid-Term Load Forecasting in Distribution System Using Copula
}

\author{
Taha Ahmadi, Carlos Alberto Cristancho Rivera \\ Mechanical engineering faculty, Universidad ECCI, Bogotá, Colombia
}

\begin{abstract}
Short-term and (Mid $\backslash$ Long)-term load prediction are needed for the efficient management of distribution system. An accurate load forecasting could help distribution operators to achieve a great control and flexibility on energy. In addition, a reliable prediction would have significant impact on load power flow problems, operation management, planning, automation, and search market. This paper proposes a new method based on copula for Short-term, and (Mid/Long)-term load forecasting. Proposed method was used less historical data to predict the load consumption then the other methods, so it is useful in distribution system due to scarce installed meters. Copula is a recently developed statistical theory for multivariate probability analysis that has been proposed by Sklar in 1958. Copulas are used in popularity for financial and reliability application. Numerical tests results using database of Iran system's operation (ISO) shows that this method provides a much better prediction performance in comparison with other methods employing the same data.
\end{abstract}

Key-Words - Gaussian Copula, student's t copula, short-term load forecasting, Mid-term load forecasting.

Received: January 7, 2020. Revised: June 20, 2020. Accepted: July 1, 2020. Published: July 15, 2020.

\section{Nomenclature}

\begin{tabular}{|c|c|}
\hline $\mathrm{m}$ & Number of variables \\
\hline $\mathrm{C}$ & multivariate distribution functions \\
\hline $\mathrm{H}$ & $\begin{array}{l}\text { the joint probability distribution of } \\
m \text { variables }\end{array}$ \\
\hline$\tau$ & the Kendall correlation \\
\hline$O$ & The spearman correlation \\
\hline U & standard uniform random variables \\
\hline Rho & correlation matrix \\
\hline$\varphi^{-1}$ & $\begin{array}{l}\text { is the inverse cumulative } \\
\text { distribution function }\end{array}$ \\
\hline$\varphi_{\mathrm{m}}$ & $\begin{array}{l}\text { is the m-dimensional standard } \\
\text { multivariate Student's t distribution }\end{array}$ \\
\hline$v$ & degrees of freedom \\
\hline HQIC & $\begin{array}{l}\text { Hannan-Quinn Information } \\
\text { Criterion }\end{array}$ \\
\hline AIC & Akaike Information Criterion \\
\hline ICDF & $\begin{array}{l}\text { inverse cumulative distribution } \\
\text { function }\end{array}$ \\
\hline $\mathrm{CDF}$ & cumulative distribution function \\
\hline PDF & Probability distribution function \\
\hline$\rho_{\mathrm{p}}$ & the Pearson correlation \\
\hline$L_{i}^{j}$ & $\begin{array}{l}\text { represent load consumption in the } i^{\text {th }} \\
\text { hour of the } j^{\text {th }} \text { day }\end{array}$ \\
\hline $\mathrm{z}$ & Number of selected days \\
\hline $\mathrm{m}_{\mathrm{f}}$ & defined vectors \\
\hline$\beta_{\mathrm{j}}^{\mathrm{i}}$ & Rank correlation \\
\hline STLF & Short-term load forecasting \\
\hline MTLF & Mid-term load forecasting \\
\hline
\end{tabular}

$\begin{array}{ll}\text { MAPE } & \begin{array}{l}\text { Mean absolute percentage error } \\ \mathrm{D}^{\mathrm{td}}\end{array} \\ \mathrm{D}^{\mathrm{tm}} & \begin{array}{l}\text { the hourly demand of the day } \\ \text { the hourly demand of the next day }\end{array} \\ \theta^{\text {td }} & \begin{array}{l}\text { the hourly temperature of the day } \\ \text { the hourly load consumption of the }\end{array} \\ \mathrm{d}_{\mathrm{i}} & \begin{array}{l}\text { day } \\ \text { the maximum daily temperature of }\end{array} \\ \mathrm{TM}_{\mathrm{i}} & \begin{array}{l}\text { the month } \\ \text { the maximum daily demand of the }\end{array} \\ \mathrm{DM}_{\mathrm{i}} & \begin{array}{l}\text { month } \\ \end{array}\end{array}$

\section{Introduction}

Short/long term load forecasting is important for the power grid efficient operation. This data is needed to determine which power generation source should be utilized for the next hour, day or month.

Demand forecasting is an essential instrument for effective operation and planning of power systems. Depending on the time horizon, load forecasting can be usually categorized as short-term, mid-term, and long-term load forecasting. Short-term load forecasting (STLF) is defined as the prediction of load over an interval usually ranges from an hour to one week. The STLF is basically necessary for power system operation as well as many distribution system operations like load power flow, energy transactions, maintenance scheduling, and reliability analysis. Accurate load prediction in distribution system will lead to a set of vital information that helps transmission owners, generation operators and retailers to maximize their profits, achieving lower operating costs and enhancing reliability of the 

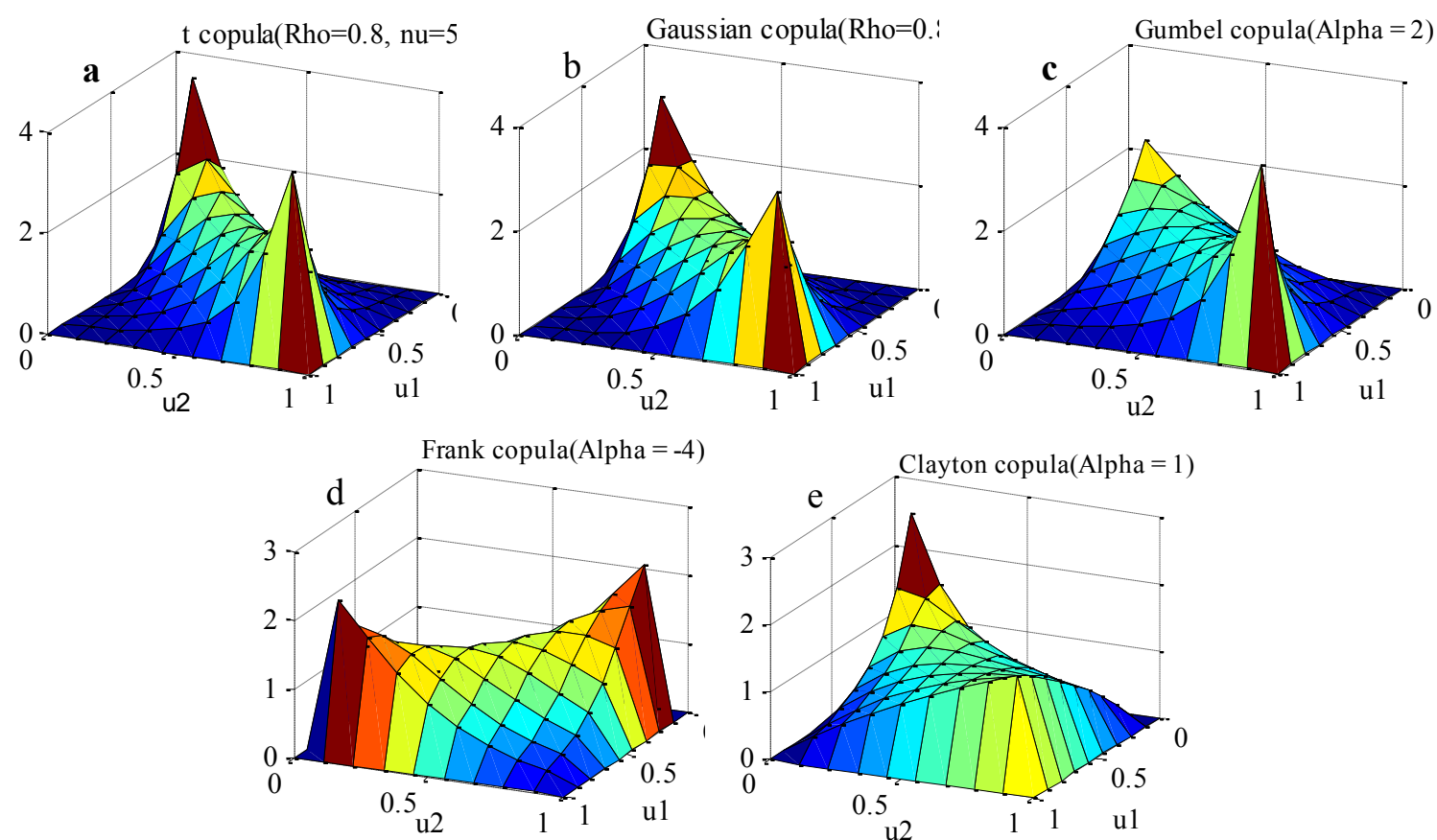

Fig.1. Sample of different bivariate copula functions: (a) t copula $(R h o=0.8, v=5)$; (b) Gaussian copula $($ Rho $=0.8) ;($ c) Gumbel copula $($ Alpha $=2) ;($ d) Frank copula (Alpha $=-4) ;($ e) Clayton copula (Alpha = 1)

electricity supply [5]. In particular, appearance of free market of the electric power necessitates demand prediction more than ever. Generally, mid/long-term demand prediction is corresponding to the forecasting horizon from a few weeks to several years [6]. (Mid/Long)-term Load forecasting (MTLF) in distribution systems is necessary to forecast the load growth of all substations and feeders in a limited region for the next several months or years, MTLF is used for distribution system planning includes the sitting and capacity of substations. Solving many important problems such as transmission augmentation or routing of feeders, which are relating to the locations and amounts of future load growth, therefore load prediction, is the basic of optimal distribution system operation and planning. Meanwhile, forecasting error has significant cost implications for players in competitive power markets. Accurate load forecasting would also have a significant impact on the production costs, utility operation, and overload prevent on and efficient energy storage. Additionally, an improvement in the range of a few percentages in prediction accuracy results in better system security, higher reliability and savings worth up to millions of dollars as well [7]. Therefore, a wide variety of forecasting models have been suggested, which can be divided into three categories; statistical methods, evolutionary techniques, and end use models. The end use method is the most expensive and complicated which needs a lot of man-power to achieve the data by types of load component and customer. Statistical methods are widely adopted, including time series and linear regression models. However, these models need more attention when the weather factors are involved in the load pattern [8-10]. Also, Box-Jenkins models [11], exponential smoothing models [12, 13], stochastic process, Kalman filters [11] and ARMA models [14] are among statistical methods. Generally, most of the statistical methods are based on linear analysis [15], while electricity demand is non-linear and sensitive to wide variables such as calendar, temperature, humidity, wind speed, and etc [16]. In addition statistical methods process numerical information, predicting current value of a variable using a mathematical combination of the last information of that variable with those of the last or current information of other variables, while measurements have been rarely performed in distribution network. Heuristically methods have recently been incorporated to the nonlinearity of electricity demand series such as artificial neural networks (ANN), fuzzy logics [17], expert systems, and hybrid models [5-18]. Also, ANN or a combination of ANN and fuzzy logic, expert systems or hybrid models have been proposed to predict the load that have complications in modeling and implementation $[6,15,16,19,20]$. However, statistical models require load modeling; they often manage their predictions using linear analysis. Intelligent systems (e.g. the ANN) need no load modeling; they can learn the load profiles from the 
Table1. Characteristics of alternative copula and their measures of dependence

\begin{tabular}{|c|c|c|c|}
\hline Copula & Dependence structure characteristics & $\begin{array}{c}\text { Archimedean } \\
\text { generation } \\
\text { function }\end{array}$ & $\begin{array}{c}\text { Relation between the copula } \\
\text { parameter and the Kendall's } \tau \\
\text { coefficient }\end{array}$ \\
\hline Gaussian & $\begin{array}{c}\text { symmetric about center point, weak tail } \\
\text { dependencies, left and right tail } \\
\text { dependencies go to zero at extremes }\end{array}$ & - & $\begin{array}{c}R h o=\sin \left(\frac{\pi \tau}{2}\right) \\
\tau \in[-1,1]\end{array}$ \\
\hline $\mathrm{t}$ & $\begin{array}{c}\text { symmetric about center point, weak tail } \\
\text { dependences, left and right tail } \\
\text { dependencies go to zero at extremes }\end{array}$ & - & $R h o=\sin \left(\frac{\pi \tau}{2}\right)$ \\
Clayton & $\begin{array}{c}\text { symmetric about center point, strong left tail } \\
\text { dependence and weak right tail dependence, right tail } \\
\text { dependence goes } \\
\text { to zero at right extreme }\end{array}$ & $\frac{1}{\theta}\left(\mathrm{t}^{-\theta}-1\right)$ & $\theta=\frac{2 \tau}{1-\tau}$ \\
\hline Gumbel & $\begin{array}{c}\text { symmetric about center point, strong right dependence, } \\
\text { weak left tail dependence, left tail dependence goes to } \\
\text { zero at left extreme }\end{array}$ & $(-\ln \mathrm{t})^{\theta}$ & $\tau \in(0,1)$ \\
\hline Frank & $\begin{array}{c}\text { symmetric about center point, very weak tail } \\
\text { dependencies, left and right tail dependencies go to } \\
\text { zero at extremes }\end{array}$ & $-\ln \frac{\exp (-\theta \mathrm{t})-1}{\exp (-\theta)-1}$ & $\begin{array}{c}\theta=\frac{1}{1-\tau} \\
\tau \in[0,1)\end{array}$ \\
\hline
\end{tabular}

history of the load, so it should also be noted that most of the artificial intelligence based models not only are complex both in design and implementation [16], but also need a lot of historical data base to learn the load profiles. The major disadvantage of the ANN methods to forecasting demand in distribution system is their ability to find nonlinear relationships between the load and the parameters that influence the load using huge amount of historical dataset [15], while measurements have been rarely performed due to the vastness of distribution system. In addition there are certain limitations in using heuristically methods for example ANN including difficulty in determining the best network topology and training parameters (the number and size of the hidden layers), the training rate, the type of neuron transfer functions for the various layers, momentum coefficient, and training stopping criteria to avoid over-fitting while ensuring adequate data generation [14]. Copula is a recently developed statistical theory for multivariate probability analysis that has been proposed by Sklar in 1958 [21]. Copulas are functions that link multivariate distribution to their univariate functions, and they are widely used for financial and reliability application for example, in [22] it is proposed a method using copula to predict demand for natural gas of retail consumers. In this paper, a new method was proposed using $t$ and Gaussian (Normal) copula to predict demand in short term period, and another method was suggested to forecast peak demand in (mid/long) term period. The proposed method, unlike another statistical method provides accurate analysis for non-linear data that has been widely used among multivariate data. In addition, according to the results of the simulation the proposed method requires much less historical data then the other methods to predict.

\section{Principles of Copulas and dependence}

\subsection{Definition of copulas}

Copulas are functions that join or couple multivariate distribution functions to their one-dimensional marginal distribution functions. Alternatively, copulas are multivariate distribution functions (C) of $\mathrm{m}$ variables whose one-dimensional marginal distributions are uniform within the interval $(0,1) \mathrm{m}$ with the following properties [21]:
a)
m;
b) $\quad \mathrm{C}(\mathrm{u} 1, \mathrm{u} 2, \ldots, \mathrm{um})$ is increasing in each component uj, $\mathrm{j} \in\{1,2, \ldots, \mathrm{m}\}$
c) The range of $\mathrm{C}$ is the unit interval $[0,1]$;
d) $\quad$ For $u j \leq v j, 1 \leq \mathrm{j} \leq \mathrm{m}, \mathrm{C}$ satisfies the rectangle in equality [23];
$\sum_{0}^{2} \mathrm{j}_{1}=1 \cdots \sum_{\mathrm{j}_{\mathrm{m}}=1}^{2}(-1)^{\mathrm{j}_{1}+\cdots+\mathrm{j}_{\mathrm{m}}} \mathrm{C}\left(\mathrm{u}_{1, \mathrm{j}_{1}}, \ldots, \mathrm{u}_{\mathrm{m}, \mathrm{j}_{\mathrm{m}}}\right) \geq$

Where, $\mathrm{m}$ is the number of dependent outcomes that should be modeled and all marginal distributions of the random vector ( $\mathrm{u} 1, \mathrm{u} 2 \ldots, \mathrm{um})$.

It can be showed from the definition that copulas are capable of describing nonlinear dependence among multivariate data in isolation from their marginal probability distributions [21]. Copulas can also serve as a powerful tool for both modeling and simulating nonlinearly-interrelated multivariate data, and uniform continuity and existence of all partial derivatives [24]. Some samples of t, Gaussian, Gumbel, Frank, and Clayton copulas are illustrated in Fig. 1 in bivariate form [25]. Consider the joint probability distribution of $\mathrm{m}$-random variables $\mathrm{Xi}(\mathrm{i}$ $=1, \ldots, \mathrm{m}), \mathrm{H}(\mathrm{x} 1, \ldots, \mathrm{xm})$;

$\mathrm{H}\left(\mathrm{x}_{1}, \mathrm{x}_{2}, \cdots, \mathrm{x}_{\mathrm{m}}\right)=\operatorname{Pr}\left(\mathrm{X}_{1} \leq \mathrm{x}_{1}, \mathrm{X}_{2} \leq \mathrm{x}_{2}, \cdots, \mathrm{X}_{\mathrm{m}} \leq\right.$ $\left.x_{m}\right)$ 
Where continuous marginal probability distributions are denoted by $\mathrm{Fi}(\mathrm{xi})=\operatorname{Pr}(\mathrm{Xi} \leq \mathrm{xi})=$ ui. According to [21], Sklar's theorem dictates that the relationship between $\mathrm{H}(\mathrm{x} 1, \ldots, \mathrm{xm})$ and $\mathrm{Fi}(\mathrm{xi})(\mathrm{i}=1, \ldots, \mathrm{m})$ can be established by using the copula function $\mathrm{Cm}(\mathrm{u} 1$, ..., um) as follows:

$$
\begin{gathered}
H\left(x_{1}, x_{2}, \cdots, x_{m}\right)= \\
C^{m}\left[F_{1}\left(x_{1}\right), F_{2}\left(x_{2}\right), \ldots, F_{m}\left(x_{m}\right)\right]= \\
C^{m}\left(u_{1}, u_{2}, \cdots, u_{m}\right)
\end{gathered}
$$

In mathematical terms, a copula function $\mathrm{Cm}(\mathrm{u} 1, \ldots$, $\mathrm{um})$ is the m-dimensional probability distribution on a unit hypercube $[0,1] \mathrm{m}$ with uniform marginal probability distributions on $[0,1]$, and is defined as [24]:

$$
\begin{aligned}
& \mathrm{C}^{\mathrm{m}}\left(\mathrm{u}_{1}, \mathrm{u}_{2}, \cdots, \mathrm{u}_{\mathrm{m}}\right)=\operatorname{Pr}\left(\mathrm{U}_{1} \leq \mathrm{u}_{1}, \mathrm{U}_{2} \leq\right. \\
& \left.\mathrm{u}_{2}, \cdots, \mathrm{U}_{\mathrm{m}} \leq \mathrm{u}_{\mathrm{m}}\right)
\end{aligned}
$$

Where um represents a sample of a standard uniform random variables Ui $(i=1, \ldots, m)$. According to Sklar's theorem [21], each continuous multivariate distribution $\mathrm{F}$ can be expressed in the form of (5); i.e., using a copula representation can couple multivariate distribution functions to their corresponding marginal distribution functions. He also showed that if the marginal distributions are continuous, then there is a unique copula representation. Otherwise, the copula $\mathrm{Cm}$ is uniquely determined on Ran F1, Ran F2, ..., Ran Fm, where Ran denotes "range". To apply a copula in practice, $\mathrm{m}$ uniform (on the unit interval) random variables, $U 1, \mathrm{U} 2, \ldots, \mathrm{Um}$ should be considered like a simulation study. Here, $m$ is the number of outcomes that you wish to understand. Unlike many simulation applications, we assume that $\mathrm{u} 1, \mathrm{u} 2 \ldots \mathrm{um}$ are dependent. This relationship is described through their joint distribution function, $\mathrm{H}$ $(\mathrm{x} 1, \mathrm{x} 2 \ldots \mathrm{xm})$, which can be achieved by follows [26]:

$$
\mathrm{C}^{\mathrm{m}}\left[\mathrm{F}_{1}\left(\mathrm{x}_{1}\right), \mathrm{F}_{2}\left(\mathrm{x}_{2}\right), \ldots, \mathrm{F}_{\mathrm{m}}\left(\mathrm{x}_{\mathrm{m}}\right)\right]=\mathrm{F}\left(\mathrm{x}_{1}, \mathrm{x}_{2}, \ldots, \mathrm{x}_{\mathrm{m}}\right)
$$

Where the function $\mathrm{Cm}$ is a copula, $\mathrm{U}$ is a uniform random variable and $\mathrm{u}$ is the corresponding to the actual data corresponding realization. To complete the construction, arbitrary marginal distribution functions F1(x1), F2(x2), ..., Fm (xm) were selected. Then, the function defines a multivariate distribution function, evaluated at $\mathrm{x} 1, \mathrm{x} 2, \ldots, \mathrm{xm}$ with marginal distributions F1, F2, ..., Fm .

The linear correlation coefficient, Pearson correlation, based on the covariance of two variables is not preserved by copulas. That is, two pairs of correlated variables with the same copula can have different correlations. However, the Kendall correlation, usually denoted by $\tau$, and spearman correlation, denoted by $\rho$ are a constant of the copula (6-7). That is, any correlated variables with the same copula will have the $\tau$ or $\rho$ of that copula.

$$
\begin{aligned}
& \tau= \\
& 4 \iint_{[0,1]^{\mathrm{m}}} \mathrm{C}\left(\mathrm{u}_{1}, \mathrm{u}_{2}, \ldots, \mathrm{u}_{\mathrm{m}}\right) \frac{\partial^{2} \mathrm{C}}{\partial \mathrm{u}_{1} \partial \mathrm{u}_{2} \ldots \partial \mathrm{u}_{\mathrm{m}}} d \mathrm{u}_{1} \mathrm{du} \mathrm{u}_{2} \ldots \mathrm{du} \mathrm{u}_{\mathrm{m}}- \\
& 1 \\
& \rho=12 \iint_{[0,1]^{\mathrm{m}}} \mathrm{C}\left(\mathrm{u}_{1}, \mathrm{u}_{2}, \ldots, \mathrm{u}_{\mathrm{m}}\right) \mathrm{du}_{1} \mathrm{du}_{2} \ldots \mathrm{du}_{\mathrm{m}}-
\end{aligned}
$$$$
1
$$

\subsection{Measuring Correlations}

To measure the strength of dependence between random variables, a measure of dependence is required. In [1], dependence refers to any statistical relationship between two random variable or two sets of data; correlation refers to any of a broad class of statistical relationships involving dependence. There are several definitions for the correlation coefficients in order to measure the degree of dependence. One well-known definition for measuring dependence is the Pearson correlation coefficient, which measures the degree of linear relationship between the random variables; and is fixed to linear transformations [27]. However, it has several disadvantages; in general, a non-linear scale transformation is applied to the multivariate distribution. Thus, the calculated correlations before and after the transformation (see (8)) results are in different values. Moreover, the Pearson correlation is not defined for some heavytale distributions, where momentums do not exist, and values of correlation ( $\rho p)$ depend on the marginal distributions of $\mathrm{X}$ and $\mathrm{Y}$. Therefore, a rank correlation coefficient, such as Kendall's $\tau$ or Spearman's $\rho$, is more appropriate to fulfill the desirable characteristics of a measure of dependence.

$\rho_{\mathrm{p}}(\mathrm{X}, \mathrm{Y})=\operatorname{cov}(\mathrm{X}, \mathrm{Y}) / \sqrt{ }\left(\delta^{\wedge} 2(\mathrm{X}) \cdot \delta^{\wedge} 2(\mathrm{Y})\right)$

\subsubsection{Kendall Correlation Coefficient}

The Kendall correlation, $\tau$, represents the difference between probabilities of concordant and disconcordant pairs [28]. Let (ai, bi) and (aj, bj) be a set of joint observations from two random variables $A$ and $B$ respectively. Then, (ai, bi) and (aj, bj) are called concordant if the ranks for both elements agree: that is, if $((a i<a j) \leftrightarrow(b i<b j))$ or $((a i>a j) \leftrightarrow$ $(b i>b j))$. On the other hand, (ai, bi) and (aj, bj) are called disconcordant if $((a \mathrm{a}<\mathrm{aj}) \leftrightarrow(\mathrm{bi}>\mathrm{bj}))$ or $((\mathrm{ai}$ $>$ aj) $\leftrightarrow($ bi $<$ bj)). In other words, (ai, bi) and (aj, bj) are called either concordant or discordant, if $(a i-b j)$ $\times(a i-b j)$ is either positive or negative, respectively. Assume A and B are continuous random variables. 
Let (ai, bi), $(i=1, \ldots, n)$ represent $n$ random observations of (A, B ). Among $n(n-1) / 2$ distinct pairs, let $e$ and $f$ is the number of concordant and disconcordant, respectively. Then, the Kendall coefficient, $\tau$, is defined for this sample as below:

$$
\tau=(e-f) /(e+f)=2(e-f) / n(n-1)
$$

The Kendall correlation, $\tau$, or Spearman correlation, $\rho$, is one of the most accurate methods in estimating the copula parameter, which can be expressed as (67). Hence, the parameter Rho of the Normal (Gaussian) copula can be estimated as Rho which is equal to $\sin (\pi . \tau / 2)$, and the parameter $\theta$ of the Gumbel copula as $\theta=1 /(1-\tau)$. Other methods and more details for estimation of the copula parameter are summarized in Table 1.

\begin{tabular}{|l|l|l|l|l|l|l|l|}
\hline $\mathrm{L}_{1}{ }^{\mathrm{j}}$ & $\mathrm{L}_{2}{ }^{\mathrm{j}}$ & $\mathrm{L}_{3}{ }^{\mathrm{j}}$ & $\ldots$ & $\mathrm{L}_{\mathrm{i}}^{\mathrm{j}}$ & $\ldots$ & $\mathrm{L}_{23}{ }^{\mathrm{j}}$ & $\mathrm{L}_{24}{ }^{\mathrm{j}}$ \\
\hline
\end{tabular}

Fig. 2: general form of hourly load consumption for

\begin{tabular}{|c|c|c|c|c|c|c|c|c|}
\hline & $\mathrm{m} 1$ & $\mathrm{~m} 2$ & $\mathrm{~m} 3$ & $\cdots$ & $\mathrm{mf}$ & $\cdots$ & $\mathrm{m} 23$ & $\mathrm{~m} 24$ \\
\hline $\mathrm{m} 1$ & 1 & $\beta_{1}^{2}$ & $\beta_{1}^{3}$ & $\cdots$ & $\beta_{1}^{\mathrm{f}}$ & $\cdots$ & $\beta_{1}^{23}$ & $\beta_{1}^{24}$ \\
\hline $\mathrm{m} 2$ & $\beta_{2}^{1}$ & 1 & $\beta_{2}^{3}$ & $\cdots$ & $\beta_{3}^{1}$ & $\cdots$ & $\beta_{2}^{23}$ & $\beta_{2}^{24}$ \\
\hline $\mathrm{m} 3$ & $\beta_{3}^{1}$ & $\beta_{3}^{2}$ & 1 & $\cdots$ & $\beta_{3}^{1}$ & $\cdots$ & $\beta_{3}^{23}$ & $\beta_{3}^{24}$ \\
\hline$\vdots$ & $\cdots$ & $\cdots$ & $\cdots$ & $\ddots$ & $\cdots$ & $\cdots$ & $\cdots$ & $\cdots$ \\
\hline $\mathrm{mf}$ & $\beta_{\mathrm{f}}^{1}$ & $\beta_{\mathrm{f}}^{2}$ & $\beta_{\mathrm{f}}^{3}$ & $\cdots$ & 1 & $\cdots$ & $\beta_{\mathrm{f}}^{23}$ & $\beta_{\mathrm{f}}^{24}$ \\
\hline$\vdots$ & $\cdots$ & $\cdots$ & $\cdots$ & $\cdots$ & $\cdots$ & $\ddots$ & $\cdots$ & $\cdots$ \\
\hline $\mathrm{m} 23$ & $\beta_{23}^{1}$ & $\beta_{23}^{2}$ & $\beta_{23}^{3}$ & $\cdots$ & $\beta_{23}^{\mathrm{f}}$ & $\cdots$ & 1 & $\beta_{23}^{24}$ \\
\hline $\mathrm{m} 24$ & $\beta_{24}^{1}$ & $\beta_{24}^{2}$ & $\beta_{24}^{3}$ & $\cdots$ & $\beta_{24}^{\mathrm{f}}$ & $\cdots$ & $\beta_{24}^{23}$ & 1 \\
\hline
\end{tabular}

Fig. 3: general form of the rank correlation 24 dimensional matrix.

\subsection{Elliptical copulas}

The Gaussian and Student's t copulas are known as elliptical copulas. The Gaussian (Normal) copula is the most familiar among all copulas, and is distributed over the unit cube $[0,1] \mathrm{m}$. The $\mathrm{m}$ dimensional Normal copula is defined as:

$$
\begin{aligned}
& \mathrm{C}^{\mathrm{m}}\left(\mathrm{u}_{1}, \mathrm{u}_{2}, \cdots, \mathrm{u}_{\mathrm{m}} ; R h o\right)= \\
& \varphi_{\mathrm{m}}\left(\varphi^{-1}\left(\mathrm{u}_{1}\right), \varphi^{-1}\left(\mathrm{u}_{2}\right), \cdots, \varphi^{-1}\left(\mathrm{u}_{\mathrm{m}}\right) ; R h o\right)
\end{aligned}
$$

Where $\varphi-1($.$) is the inverse cumulative distribution$ function (CDF) of a standard normal distribution function $\varphi($.$) , and \varphi m(. ; R h o)$ is the m-dimensional standard multivariate normal distribution function with mean vector zero and covariance matrix equal to the correlation matrix, Rho. Closely related to the Gaussian (Normal) copula is the t-copula,

$\mathrm{C}^{\mathrm{m}}\left(\mathrm{u}_{1}, \mathrm{u}_{2}, \cdots, \mathrm{u}_{\mathrm{m}} ; R h o, v\right)=$ $\varphi_{\mathrm{m}}\left(\varphi^{-1}\left(\mathrm{u}_{1} ; n u\right), \varphi^{-1}\left(\mathrm{u}_{2} ; n u\right), \cdots, \varphi^{-1}\left(\mathrm{u}_{\mathrm{m}} ; n u\right) ; R h o, v\right)$ (11)

Where $\varphi m$ is the m-dimensional standard multivariate Student's $t$ distribution with correlation matrix Rho and degrees of freedom parameter $\mathrm{v}>2$, and $\varphi-1$ is the inverse cumulative distribution function (ICDF) of a univariate Student's $t$ distribution with mean zero, and degrees of freedom nu. Both normal and Student's t copulas are symmetrical, and the Student's t copula converges to the Normal copula when $v$ becomes infinity, the $t$ copula assigns more probability to tail events than the Normal copula. Moreover, Student's t copula can capture lower and upper tail dependence of data [24]. To simulate dependent multivariate data using a copula must specify each of the following:

- The copula family and any shape parameters

- The rank correlations among variables and

- Marginal distribution for each variable

The copula selection between the Student's t copula and the Gaussian copula (GC) can be done by comparing the calculated values of the HannanQuinn Information Criterion (HQIC) or Akaike Information Criterion (AIC) [24-29], which is defined as:

AIC $=\left(\frac{2 \mathrm{~N}_{\mathrm{a}}}{\mathrm{N}_{\mathrm{a}}-\mathrm{K}_{\mathrm{a}}-1}\right) \mathrm{K}_{\mathrm{a}}-2 \cdot \ln \left(\mathrm{L}_{\max }\right)$

$\mathrm{HQIC}=2 \ln \left(\ln \left(\mathrm{N}_{\mathrm{a}}\right)\right) \times \mathrm{K}_{\mathrm{a}}-2 \cdot \ln \left(\mathrm{L}_{\max }\right)$

Where $\mathrm{Na}$ is the number of observations (e.g. data values), $\mathrm{Ka}$ is the number of parameters to be estimated (e.g. the normal distribution has 2 parameters: $\mathrm{mu}$ and sigma), and Lmax is the maximized value of the log-likelihood for the estimated model. A copula associated with the smallest value of the selected information criterion, is considered to be the best-fit copula [24].

\section{Load forecasting}

Studying the dependence structure of random variables is one of the most interesting topics in recent years. Methods that have been used to study the dependence of random variables were not efficient, but copula theorem is a useful method to model the dependencies between random variables. 
Copula function is a new statistical method which is help to understand the relationship between several random variables in each event, so the dependencies between random variables which have been affected demand such as temperature, sun, and humidity [30]; can be obtained using copula. Therefore, copula method can be used to predict the amount of demand in short-term, and (mid/long)-term period.

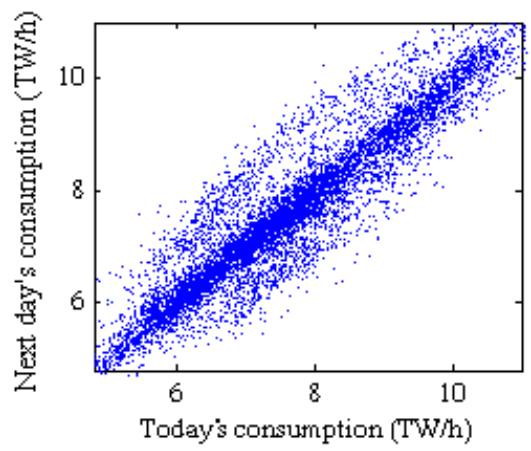

Fig. 4: Scatter plot between hourly load consumption of the day and the next day (Dtd, Dtm)

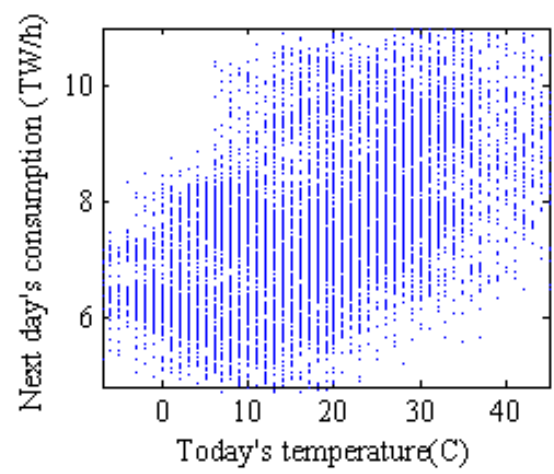

Fig. 5: Scatter plot between hourly temperature of the day and the next-day hourly demand ( $\theta \mathrm{td}$, Dtm)

\begin{tabular}{|l|l|l|l|l|l|l|l|}
\hline $\mathrm{d}_{1}$ & $\mathrm{~d}_{2}$ & $\ldots$ & $\mathrm{d}_{24}$ & $\mathrm{~d}_{25}$ & $\ldots$ & $\mathrm{d}_{47}$ & $\mathrm{~d}_{48}$ \\
\hline
\end{tabular}

Fig. 6: General form of hourly demand for two consecutive days

One of the important problems in load forecasting is to minimize prediction error by selecting the appropriate variables. In the STLF, less than a day (from an hour to several hours ahead) the prediction error of univariate models is less than multivariate models due to high inertia of temperature [24]. Univariate models are used to predict the load consumption in the next 4 to 6 hours due to unavailability or high cost of temperature forecasting in the next several hours. In the following, a new method was proposed using ( $\mathrm{t} \backslash$ Gaussian) copula to predict demand for an hour ahead as well as a day. In addition, the peak load of the next month was predicted base on the suggested model using GC. In the proposed algorithms both univariate and multivariate models have been investigated, and the results are discussed.

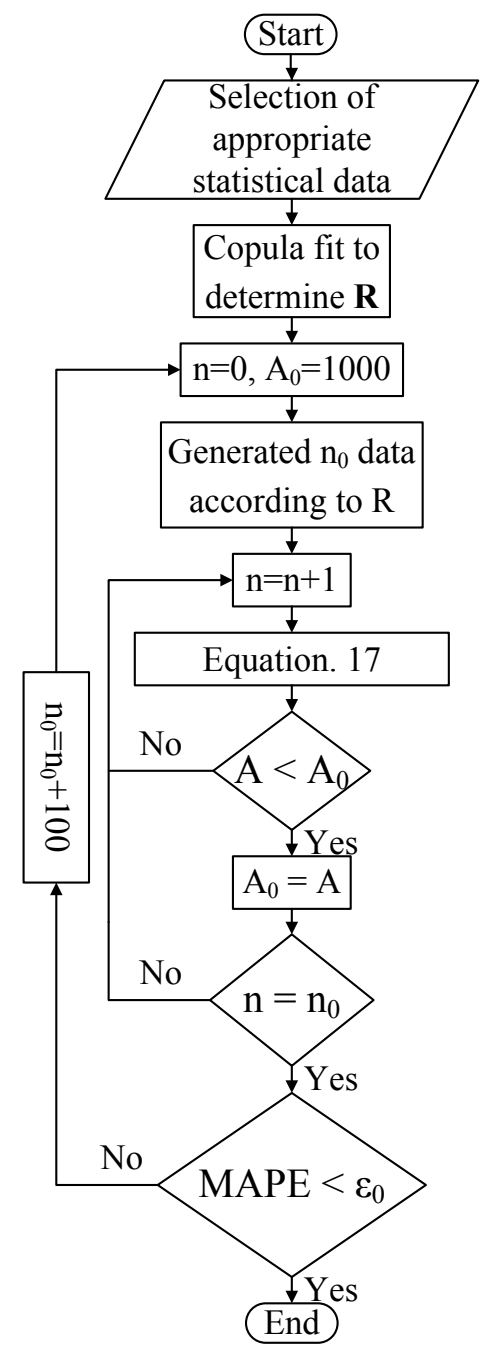

Fig. 7: the proposed algorithm to forecast the next-day demand

\subsection{Short-term load prediction for the next hour demand}

\subsubsection{Proposed the next-hour demand forecasting models}

In order to determine the parameters of copula and to predict the hourly load consumption, each day was divided into 24 equal parts, as 24 hours (Fig. 2). Where $\mathrm{L}_{\mathrm{i}}^{\mathrm{j}}$ represent load consumption in the $i_{\text {th }}$ hour of the $j_{\text {th }}$ day. In order to predict accurately demand, the same days were separated of each other in a week. As hourly load changing, load profile, of the same day was almost identical. For example, the days have been classified in two parts: working days and nonworking days. Also, usually the day of the week in 
order to improve load forecasting accuracy can be divided into four categorized: holidays, a day before the holiday, a day after the holiday, and the rest day of the week. For example the day of the week in Iran categorized into four parts: Fridays, Thursdays, Saturdays, and other days of the week. For STLF in the $i_{\text {th }}$ hour of the $j_{\text {th }}$ day, above to 4 days similar to the $j_{\text {th }}$ day was chosen; while the distance between them and the $j_{\text {th }}$ day is less than 45 days. Considering the hourly loads of selected days as a vector, mf, which was defined as follows:

$m_{f}=\left[L_{f}^{j}, L_{f}^{j-1}, L_{f}^{j-2}, \cdots, L_{f}^{j-z}\right], f=1,2, \ldots, 24$

Where $\mathrm{z}$ is the number of selected days. 24 vectors defined as (' $\mathrm{m}_{\mathrm{f}}$ '), therefore 24 variables were considered; the defined random variables were correlated with each other. In other words, the amounts of load consumption at different times have been correlated with each other. Therefore, changes in electric power consumption at the specific time shows changing demand in other times. As before mentioned, according to the Sklar's theorem the parameters of the copula, coefficient matrix, can be estimated by means of an approximation to Kendall's or spearman's rank correlation which represents rank correlation among variables. In the following the proposed method was presented using copula to forecast the next hour consumption.

Proposed algorithm for STLF in this paper is as follows:

1- Fit appropriate marginal distribution to variables $\mathrm{m}_{\mathrm{f}}(\mathrm{f}=1,2, \ldots, 24)$;

2- According to previous step use appropriate CDF to transform actual variables to $\mathrm{U}_{\mathrm{w}} \in[0,1], \mathrm{w}=1$, $2, \ldots 24$;

3- Rank correlation: Kendall's Rank correlation $(\tau)$ or Spearman's rank correlation ( $\rho)$ was calculated for the variables $(6,7)$;

4- The parameters of the ( $t /$ Gaussian) copula were calculated by Kendall's Rank correlation $(\tau)$ or Spearman's rank correlation ( $\rho$ ) among 24 variables. It should be noted that the correlation matrix, Rho, dictate the parameters of the Gaussian or Student's t copula, when satisfy positive semi-definiteness constraint. Rank correlation matrix, which was obtained in this step, is a matrix with dimensions $24 \times 24$ because of the 24 defined variables. Fig. 3 shows the general form of the rank correlation matrix with dimensions $24 \times 24$. For example $\beta_{1}^{2}$ illustrates the rank correlation between the variables $\mathrm{ml}$ and $\mathrm{m} 2$;
5- Produce sufficient data on a unit hypercube $[0,1] 24$ with uniform marginal probability distributions, Usimulation, according to the characteristics of the Gaussian (Rho) or Student's $\mathrm{t}(\mathrm{Rho}, \mathrm{v})$ copula which is equal to $\sin (\pi \cdot \tau / 2)$

6- an appropriate ICDF function was used base on step 1 to transform Usimulation to simulated random variables, which were the same characteristics as well as actual variables;

7- According to the correlation matrix, Rho, which was obtained from the previous steps, each random variable was more dependence with one of the other variables. If $\beta_{\mathrm{j}}^{\mathrm{i}}$ is the greatest rank correlation in the jth row when $(i<j)$, therefore the ith hour demand was used to forecast the jth hour load consumption;

8- In order to predict demand in the jth hour of the day, the amount of the load consumption in the ith time of the same day was considered. Corresponding to the load consumed in the ith hour, the jth data from data sets, which was generated in step six, was selected. Selected Data was considered as the load forecasting in the jth hour.

\subsection{STLF for the next-day demand}

As mentioned, changing temperature affect the amount of demand, but in the short-term load forecasting ( 4 to 6 hour ahead) it can be ignored. In contrast, temperature variations were considered to predict the next-day hourly demand. Therefore, in order to predict next-day electricity demand, rank correlation between load consumption and temperature for each hour of the day and the next day was calculated. In this paper the hourly demand and temperature in 2018 was considered. It is noteworthy that it is possible to use any other type of data and the change of year and month has no effect on the performance of the proposed method. If there is statistical dependence between the above mentioned variables, the measure of rank correlation is applied. The rank correlation measures a monotonic relationship between variables. Rank correlation calculated for the variables: $\mathrm{D}_{\mathrm{td}}, \theta_{\mathrm{td}}$ and $\mathrm{D}_{\mathrm{tm}}$ in 2018 were given by:

$\mathrm{R}^{\mathrm{r}}=\left[\begin{array}{lll}1.00 & 0.34 & 0.34 \\ 0.34 & 1.00 & 0.76 \\ 0.34 & 0.76 & 1.00\end{array}\right]$

Where Dtd, and Dtm is the hourly demand of the day, and the next day, respectively; and Otd is the hourly temperature of the day. A GC is a popular option for modeling the dependence structure between variables [31]. Parameters of the GC functions Rho are 
Table 2: characteristic of 24 variables Gaussian copulas

\begin{tabular}{|c|c|c|c|c|c|c|c|c|c|c|c|c|c|c|c|c|c|c|c|c|c|c|c|c|}
\hline & $\mathbf{m}_{1}$ & $\mathbf{m}_{2}$ & $\mathbf{m}_{3}$ & $\mathbf{m}_{4}$ & $m_{5}$ & $\mathbf{m}_{6}$ & $\mathbf{m}_{7}$ & $\mathbf{m}_{8}$ & m9 & $\mathbf{m}_{10}$ & $\mathbf{m}_{11}$ & $\mathbf{m}_{12}$ & $\mathbf{m}_{13}$ & $\mathbf{m}_{14}$ & $\mathbf{m}_{15}$ & $\mathbf{m}_{16}$ & $\mathbf{m}_{17}$ & $\mathbf{m}_{18}$ & $\mathbf{m}_{19}$ & $\mathbf{m}_{\mathbf{2 0}}$ & $\mathbf{m}_{21}$ & $\mathbf{m}_{22}$ & $\mathbf{m}_{23}$ & $\mathbf{m}_{24}$ \\
\hline $\mathbf{m}_{1}$ & 1 & $\underline{0.85}$ & 0.83 & 0.79 & 0.79 & 79 & 75 & 74 & 71 & 75 & 0.70 & 0.82 & 0.83 & 0.77 & 0.58 & 0.65 & 0.68 & 0.55 & .63 & 59 & 0.59 & 0.61 & 51 & 61 \\
\hline $\mathbf{m}_{2}$ & 0.85 & 1 & $\underline{0.92}$ & 86 & 91 & 91 & 86 & .73 & 77 & 0.86 & 0.77 & 0.80 & 0.83 & 0.78 & 0.63 & 0.66 & 0.61 & 0.60 & .68 & 62 & 0.66 & 65 & 46 & .55 \\
\hline $\mathbf{m}_{3}$ & .83 & .92 & 1 & 96 & 97 & 0.98 & 94 & 88 & 91 & 0.93 & 0.87 & 0 & 2 & \begin{tabular}{|l|}
0.87 \\
\end{tabular} & 0.73 & 0.76 & .73 & .78 & 82 & 77 & .79 & 76 & 61 & 1.6 \\
\hline $\mathbf{m}_{4}$ & 0.79 & 86 & 96 & & 96 & & & & & & & 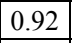 & 92 & 89 & 30 & 3 & 80 & 83 & 3 & 8 & 82 & 79 & 55 & 63 \\
\hline $\mathrm{m}_{5}$ & 79 & 91 & 97 & 96 & 1 & 0.99 & 97 & & 91 & 0.95 & \begin{tabular}{|l|}
0.91 \\
\end{tabular} & & & 0.87 & 0.76 & 0.80 & 0.76 & \begin{tabular}{|l|l|}
0.81 \\
\end{tabular} & .85 & 78 & .79 & 78 & 64 & 61 \\
\hline $\mathbf{m}_{6}$ & 0.79 & 91 & 98 & 97 & 0.99 & - & $\underline{0.97}$ & 87 & 0.91 & $\underline{0.96}$ & \begin{tabular}{|l|}
0.92 \\
\end{tabular} & 0.92 & 0.94 & 0.89 & 0.76 & 0.80 & 0.77 & \begin{tabular}{|l|}
0.83 \\
\end{tabular} & 0.87 & 8.82 & 0.82 & 82 & 67 & .67 \\
\hline $\mathbf{m}_{7}$ & 0.75 & 86 & 94 & 96 & 97 & .97 & 1 & 0.85 & 0. & 0. & & & 0.93 & 0.90 & 0.79 & 0.84 & 0.82 & $\underline{0.87}$ & 0.90 & 0.85 & 0.81 & 82 & 67 & .63 \\
\hline $\mathrm{m}_{8}$ & 74 & 73 & 88 & 84 & 85 & 87 & 85 & & 0.82 & 33 & 0 . & 0 . & 0.82 & 0.77 & 0.56 & 0.67 & \begin{tabular}{|l|}
0.68 \\
\end{tabular} & .77 & 80 & 77 & 0.7 & 69 & 64 & 59 \\
\hline m9 & 71 & 77 & 91 & 0.91 & 91 & 91 & 90 & & 1 & 0.86 & & & 0. & 0. & 0.74 & \begin{tabular}{ll|}
0.82 \\
\end{tabular} & \begin{tabular}{|l|}
0.78 \\
\end{tabular} & 82 & 86 & 77 & .76 & 31 & 71 & 71 \\
\hline $\mathbf{m}_{10}$ & 0.75 & 86 & 93 & 93 & 95 & 96 & 94 & 33 & 0.86 & 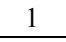 & \begin{tabular}{|l|}
0.91 \\
\end{tabular} & 0.88 & 0.90 & 0.82 & 0.72 & 0.79 & 0.74 & 0.85 & 0.86 & 0.82 & .80 & 74 & 88 & .55 \\
\hline $\mathbf{m}_{11}$ & 0.70 & 77 & 0.87 & 89 & 91 & 92 & 93 & 0.83 & 8 & 0.91 & 1 & $\underline{0.94}$ & 0.90 & 0.89 & 0.78 & 0.8 & 0.82 & \begin{tabular}{|l|}
0.84 \\
\end{tabular} & 0.88 & 0.83 & \begin{tabular}{|l|l|}
0.79 \\
\end{tabular} & 83 & 72 & .65 \\
\hline 112 & 0.82 & 80 & 0.9 & 0.92 & 0.92 & 0.92 & 91 & 0.81 & 0.87 & 0.8 & 0. & & $\underline{0.94}$ & 0.92 & 0.82 & 0.84 & 0.88 & \begin{tabular}{|l|}
0.80 \\
\end{tabular} & 0.85 & 0.81 & \begin{tabular}{|l}
0.82 \\
\end{tabular} & 84 & 72 & 73 \\
\hline $\mathbf{m}_{13}$ & 0.83 & 83 & 92 & 92 & .93 & 94 & 0.93 & & & 0. & & 0. & & $\underline{0.93}$ & 0.77 & 0.84 & \begin{tabular}{|l|}
0.83 \\
\end{tabular} & \begin{tabular}{|l|}
0.84 \\
\end{tabular} & \begin{tabular}{|l|}
0.88 \\
\end{tabular} & 0.84 & \begin{tabular}{|l|}
0.83 \\
\end{tabular} & 6 & 6 & 0.74 \\
\hline $\mathbf{m}_{14}$ & 0.77 & 78 & 0.87 & \begin{tabular}{|l|}
0.89 \\
\end{tabular} & 87 & 89 & 0.9 & 0.77 & 0.85 & 0.82 & 0.89 & 0.92 & 0.93 & -1 & $\underline{0.88}$ & $\underline{0.87}$ & 0.89 & 0.82 & 0.84 & 0.79 & 0.77 & 0.90 & 0.80 & 0.77 \\
\hline $\mathbf{m}_{15}$ & 0.58 & 0.63 & 0.73 & 80 & 0.76 & 76 & 79 & 56 & 0.74 & 0.72 & \begin{tabular}{|l|}
0.78 \\
\end{tabular} & 0.82 & 0.77 & 0.88 & & 0.85 & \begin{tabular}{|l|}
0.89 \\
\end{tabular} & \begin{tabular}{|l|}
0.70 \\
\end{tabular} & 0.68 & 0.65 & \begin{tabular}{|l|}
0.64 \\
\end{tabular} & 76 & 68 & 60 \\
\hline$n_{16}$ & 0.65 & 0.66 & 0.76 & 0.83 & 0.8 & 0.8 & 0.8 & 0.67 & 0. & 0.79 & 0 & \begin{tabular}{|l|}
0.84 \\
\end{tabular} & \begin{tabular}{|l|}
0.84 \\
\end{tabular} & 0.87 & 0.85 & 1 & $\underline{0.91}$ & \begin{tabular}{|l|}
0.85 \\
\end{tabular} & 0.82 & 0.81 & \begin{tabular}{|l|l}
0.80 \\
\end{tabular} & \begin{tabular}{|l|}
0.83 \\
\end{tabular} & 73 & 65 \\
\hline$m_{17}$ & 0.68 & 61 & 73 & 80 & 0.76 & 77 & 82 & & & 0.74 & 0 & 0.8 & 0. & 0 & 0.8 & 0.91 & & \begin{tabular}{|l|}
0.80 \\
\end{tabular} & 0.80 & 0.78 & \begin{tabular}{|l|l}
0.70 \\
\end{tabular} & 81 & 71 & 67 \\
\hline $\mathbf{m}_{18}$ & 0.55 & 60 & 0.78 & 83 & 0.81 & 83 & 0.87 & 0.7 & 0.8 & 0.85 & 0. & 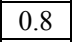 & 0.84 & 0.82 & 0.70 & 0.85 & 0.80 & & $\underline{0.96}$ & 0.95 & \begin{tabular}{|l|l}
0.89 \\
\end{tabular} & \begin{tabular}{|l|l|} 
\\
\end{tabular} & 75 & 0.64 \\
\hline $\mathbf{m}_{19}$ & \begin{tabular}{|l|}
0.63 \\
\end{tabular} & 0.68 & 0.82 & \begin{tabular}{|l|}
0.83 \\
\end{tabular} & 0.85 & \begin{tabular}{|l|}
0.87 \\
\end{tabular} & \begin{tabular}{|l|}
0.9 \\
\end{tabular} & 0.80 & 0.86 & 0.86 & \begin{tabular}{|l}
0.88 \\
\end{tabular} & 0.85 & \begin{tabular}{|l|}
0.88 \\
\end{tabular} & 0.84 & 0.68 & 0.82 & 0.80 & \begin{tabular}{|l|}
0.96 \\
\end{tabular} & 1 & $\underline{0.97}$ & \begin{tabular}{|l}
0.89 \\
\end{tabular} & $\underline{0.91}$ & \begin{tabular}{|l|}
0.77 \\
\end{tabular} & 0.69 \\
\hline $\mathbf{m}_{20}$ & \begin{tabular}{|l|}
0.59 \\
\end{tabular} & 0.62 & 0.77 & 0.8 & 0.78 & 82 & 0.85 & 0.77 & 0.77 & 0.82 & \begin{tabular}{|l|}
0.83 \\
\end{tabular} & \begin{tabular}{|l|}
0.81 \\
\end{tabular} & \begin{tabular}{|l|}
0.84 \\
\end{tabular} & 0.79 & 0.65 & 0.81 & 0.78 & \begin{tabular}{|l|}
0.95 \\
\end{tabular} & \begin{tabular}{|l|}
0.97 \\
\end{tabular} & 1 & $\underline{0.92}$ & 0.86 & 0.71 & .59 \\
\hline 121 & 0.59 & 0.66 & 0.79 & 0.82 & 0.79 & 0.82 & 0.81 & 0.7 & 0.76 & 0.80 & 0.79 & 0.82 & 0.83 & 0.77 & 0.64 & 0.80 & \begin{tabular}{|l|}
0.70 \\
\end{tabular} & \begin{tabular}{|l|}
0.89 \\
\end{tabular} & \begin{tabular}{|l|}
0.89 \\
\end{tabular} & 0.92 & 1 & 0.82 & \begin{tabular}{|l|}
0.65 \\
\end{tabular} & 0.57 \\
\hline $\mathbf{m}_{22}$ & 0.61 & 0.65 & 0.76 & 0.19 & 0.18 & 0.82 & 0.82 & 0.69 & 0.81 & 0.74 & 0.83 & 0.84 & 0.86 & 0.9 & 0.76 & 0.83 & 0.81 & \begin{tabular}{|l|}
0.88 \\
\end{tabular} & 0.91 & 0.86 & \begin{tabular}{|l}
0.82 \\
\end{tabular} & & $\underline{0.90}$ & .85 \\
\hline $\mathbf{m}_{23}$ & 0.51 & 0.46 & 0.61 & 0.65 & 0.64 & \begin{tabular}{|l|l|}
0.67 \\
\end{tabular} & 0.67 & 0.64 & 0.71 & 0.58 & 0.72 & \begin{tabular}{|l|}
0.72 \\
\end{tabular} & \begin{tabular}{|l|}
0.76 \\
\end{tabular} & 0.8 & 0.68 & 0.73 & 0.71 & \begin{tabular}{|l}
0.75 \\
\end{tabular} & \begin{tabular}{|l|}
0.77 \\
\end{tabular} & 0.71 & 0.65 & \begin{tabular}{|l|}
0.90 \\
\end{tabular} & $\overline{1}$ & $\overline{0.84}$ \\
\hline $\mathbf{m}_{24}$ & 0.61 & 0.55 & 0.64 & 0.63 & 0.67 & 0.67 & 0.63 & 0.59 & 0.71 & 0.55 & 0.65 & 0.73 & 0.74 & 0.77 & 0.60 & 0.65 & 0.67 & 0.64 & 0.69 & 0.59 & 0.57 & 0.85 & 0.84 & 1 \\
\hline
\end{tabular}

estimated by means of an approximation to Kendall's rank correlation (see table 1). This coefficient matrix has similar values to the rank correlations calculated in (15). The correlation coefficient of the GC is following as:

$$
\text { Rho }=\left[\begin{array}{lll}
1.00 & 0.51 & 0.51 \\
0.51 & 1.00 & 0.93 \\
0.51 & 0.93 & 1.00
\end{array}\right]
$$

According to the rank correlation from (15) all coefficients in the Rr matrix are appropriate. It can be observed from (16) that the hourly load consumption of the day is strongly correlated with the next day hourly demand $(\rho=0.93)$. Fig. 4 illustrates the relationship between the hourly demand of the day and the next day, which indicates strong monotonic dependence between hourly load consumption in two days. The coefficient correlation between hourly temperature of the days in 2018 and the hourly load consumption of the same days and the next days are 0.51 , which is relatively high. Fig. 5 shows the relationship between the hourly temperature of the day and the next-day demand. In order to forecast the next-day hourly demand in addition to the amount of electricity load consumption in each hour of the day, the changes in temperature of the day were also considered due to high relatively between temperature of the day and the next-day load consumption. In the following, the simulation results of the proposed models are compared.

\subsubsection{Proposed next-day demand prediction algorithms}

Hourly load consumption for two consecutive days closely to the next day was considered, according to Fig.6. Where (d1, d2, ..., d24) and (d25, d26, .., d48) dictate the hourly demand of the day and the next day, respectively. Two consecutive days have been classified in 5 parts (see Fig. 6.b); in order to predict the next day hourly demand several similar consecutive days as the day, and the next day were selected closely to them. More, the matrix copula coefficient, Rho, of the hourly load consumption of the day and the next day can be obtained due to the rank correlation of the demand for each hour of the day and the next day. In this paper, an algorithm was suggested to forecast the next day hourly demand (Fig. 7). To predict the next day load consumption, according to the proposed algorithm follow the steps below:

\begin{tabular}{|l|l|l|l|l|l|l|l|}
\hline$\theta_{1}$ & $\theta_{2}$ & $\ldots$ & $\theta_{24}$ & $\mathrm{~d}_{1}$ & $\ldots$ & $\mathrm{d}_{47}$ & $\mathrm{~d}_{48}$ \\
\hline
\end{tabular}

Fig. 8: General form of hourly load consumption and temperature for the day and the next day hourly demand

\begin{tabular}{|l|l|l|l|l|l|l|l|}
\hline$\tau_{1}$ & $\tau_{2}$ & $\ldots$ & $\tau_{30}$ & $\operatorname{dm}_{1}$ & $\ldots$ & $\operatorname{dm}_{59}$ & $\operatorname{dm}_{60}$ \\
\hline
\end{tabular}

Fig. 9: General model, which was proposed to predict the next month peak demand 
Step 1: at the first according to type of two consecutive days, the day and the next day, hourly load consumption of several same consecutive days were selected from historical demand data, closely to the next day.

Step 2: the rank correlation between variables and marginal distribution of each variable were obtained in this step.

Step 3: the parameter of the GC function, the correlation matrix, were calculated through the rank correlations among variables (table 1).

Step 4: n0 data sets were generated based on the characteristic of $\mathrm{GC}$; and the amount of $\mathrm{n}$, and $\mathrm{A} 0$ were set to 0 , and 1000 , respectively.

Step 5: n0 data sets, which were generated by GC, can be illustrate as below:

$\mathrm{D}_{1}^{\mathrm{n}}, \mathrm{D}_{2}^{\mathrm{n}}, \cdots, \mathrm{D}_{24}^{\mathrm{n}}, \mathrm{D}_{25}^{\mathrm{n}}, \cdots, \mathrm{D}_{47}^{\mathrm{n}}, \mathrm{D}_{48}^{\mathrm{n}}, \mathrm{n}=1, \ldots, \mathrm{n}_{0}$

Therefore, each data set (17) consists of the hourly load consumption for two consecutive days. In each string, the first 24 data dictate the hourly load consumption of the day and the rest of data shows the next-day hourly demand. Based on the generated data, the equation (18) was defined as follows:

$\mathrm{A}=\sum_{\mathrm{i}=1}^{24}\left(\mathrm{D}_{\mathrm{i}}^{\mathrm{n}}-\mathrm{d}_{\mathrm{i}}\right)^{2}, \mathrm{n}=1, \ldots, \mathrm{n}_{0}$

Whereas di indicates the hourly load consumption of the day; which are wanted to predict the next 24 hours demand. At this stage, a data string among n0 generated data sets was selected while minimizing the objective function (18).

$D_{1}^{b}, D_{2}^{b}, \cdots, D_{24}^{b}, D_{25}^{b}, \cdots, D_{47}^{b}, D_{48}^{b}$.

Table 3: General form of produced data sets using copula

\begin{tabular}{|c|c|c|c|c|c|}
\hline $\mathrm{m}_{1}$ & $\mathrm{~m}_{2}$ & $\mathrm{~m}_{3}$ & $\cdots$ & $\mathrm{m}_{23}$ & $\mathrm{~m}_{24}$ \\
\hline $\operatorname{Load}_{1}^{1}$ & $\operatorname{Load}_{2}^{1}$ & $\operatorname{Load}_{3}^{1}$ & $\cdots$ & $\operatorname{Load}_{23}^{1}$ & $\operatorname{Load}_{24}^{1}$ \\
\hline $\operatorname{Load}_{1}^{2}$ & $\operatorname{Load}_{2}^{2}$ & $\operatorname{Load}_{3}^{2}$ & $\cdots$ & $\operatorname{Load}_{23}^{2}$ & $\operatorname{Load}_{24}^{2}$ \\
\hline$\vdots$ & $\vdots$ & $\vdots$ & $\cdots$ & $\vdots$ & $\vdots$ \\
\hline $\operatorname{Load}_{1}^{\mathrm{k}}$ & $\operatorname{Load}_{2}^{\mathrm{k}}$ & $\operatorname{Load}_{3}^{\mathrm{k}}$ & $\cdots$ & $\operatorname{Load}_{23}^{\mathrm{k}}$ & $\operatorname{Load}_{24}^{\mathrm{k}}$ \\
\hline
\end{tabular}

Step 6, 7, and 8: if the value of A is smaller than A0 or the value of $n$ is equal to $n 0$, we go to the next step; otherwise we go back in the previous steps as shown in Fig. 7. In the eighth step, according to (19) a string of the data sets was selected whereas the first 24 data $\left(D_{1}^{b}, D_{2}^{b}, \cdots, D_{24}^{b}\right)$ was minimum distance with hourly demand of the day. Therefore, $D_{25}^{b}, \cdots, D_{47}^{b}, D_{48}^{b}$ dictate the prediction of the next-day hourly load consumption. Mean absolute percentage error
(MAPE) was calculated based on Eq. 20 for the first 24 data of the selected data set and hourly load consumption of the day. If MAPE is smaller than $\varepsilon 0$, the selected data set is appropriate in order to predict the next-day electricity consumption; otherwise according to proposed algorithm (Fig. 7), we go back to step 3 .

MAPE $=\frac{100 \%}{24} \sum_{\mathrm{t}=1}^{24}\left|\frac{\mathrm{d}_{\mathrm{t}}-\mathrm{D}_{\mathrm{t}}}{\mathrm{d}_{\mathrm{t}}}\right|$

In addition, to improve next-day demand forecasting accuracy temperature variations was considered. A general form of hourly load consumption on two consecutive days and changing temperature of the day was modeled as Fig. 8, Where $(\mathrm{d} 1, \mathrm{~d} 2, \ldots, \mathrm{d} 24)$ and $(\theta 1, \theta 2, \ldots, \theta 24)$ dictate the hourly load consumption and temperature of the day, respectively; and (d25, d26, ..., d48) illustrate the hourly load consumption of the next day. In this case, the proposed algorithm can be used to predict the next day hourly load consumption. However, the number of variables is increased to 72 .

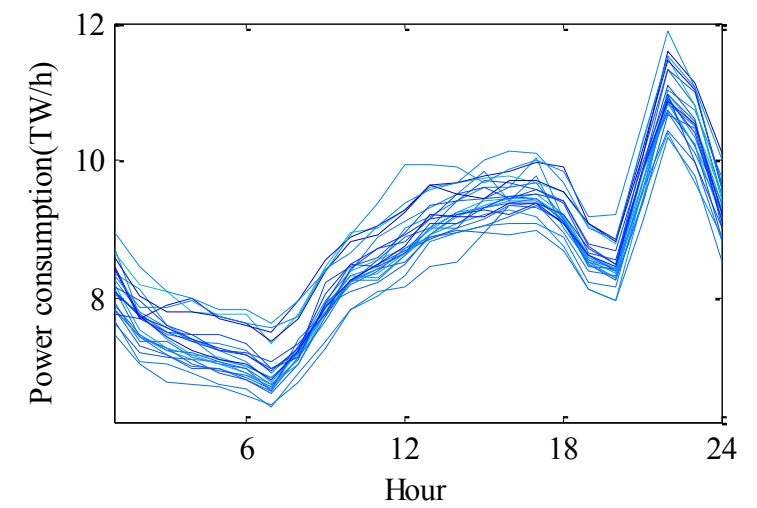

Fig. 10: Load profile of 20 similar days

\section{3 (Mid/Long)-term load forecasting model}

\subsubsection{Forecasting the next month peak demand}

At the first daily peak load consumption of the next month was predicted, and then peak load consumption of the next month was obtained. In the proposed method using GC changing temperature was also considered to increase the forecast accuracy. In Fig. 9 the peak load forecasting model was proposed for the next month where $(\tau 1, \tau 2, \ldots, \tau 30)$, $(\mathrm{dm} 1, \mathrm{dm} 2, \ldots, \mathrm{dm} 30)$ represent the maximum temperature and the maximum amount of demand on each day of the month, respectively; and $(\mathrm{dm} 31$, $\mathrm{dm} 32, \ldots, \mathrm{dm} 60$ ) illustrate the maximum daily consumption of the next month. So, as before, to predict the daily load consumption of the next month; at first, Parameters of the GC functions, Rho, are estimated by means of an approximation to Kendall's rank correlation based on historical data. Then, as the 
algorithm proposed in the previous section $\mathrm{n} 0$ data sets were generated based on Rho. According to the maximum daily temperature, and maximum daily consumption of the month a data series was selected among data sets to minimize the objective function (21).

$$
\begin{aligned}
& \mathrm{A}=\sum_{\mathrm{i}=1}^{30}\left(\left(\mathrm{DM}_{\mathrm{i}}^{\mathrm{n}}-\mathrm{dm}_{\mathrm{i}}\right)^{2}+\left(\mathrm{TM}_{\mathrm{i}}^{\mathrm{n}}-\tau_{\mathrm{i}}\right)^{2}\right), \mathrm{n}= \\
& 1, \ldots, \mathrm{n}_{0}
\end{aligned}
$$

Where TMi, and DMi show the daily maximum temperature and the daily maximum demand consumption of the month, respectively. Finally, according to Eq.21 a data sets was chosen whereas the first 60 data was minimum distance with maximum daily temperature and demand of the month, so the rest data of the selected data sets show the prediction of the next month daily peak demand.

Table 4: Min., Max., and Ave. MAPE next hour demand prediction for April 2018

\begin{tabular}{|c|c|c|c|}
\hline & Mean-MAPE & Max-MAPE & Min-MAPE \\
\hline $\begin{array}{c}\text { 1E3 Gen. data using } \\
\text { Gaussian copula }\end{array}$ & 1.37 & 4.70 & 0.02 \\
\hline $\begin{array}{c}\text { 1E5 Gen. data using } \\
\text { Gaussian copula }\end{array}$ & 0.98 & 2.46 & 0.03 \\
\hline $\begin{array}{c}\text { 1E3 Gen. data using } \\
\text { Student's t copula }\end{array}$ & 1.40 & 3.26 & 0.07 \\
\hline $\begin{array}{c}\text { 1E5 Gen. data using } \\
\text { Student's t copula }\end{array}$ & 0.91 & 2.72 & 0.16 \\
\hline
\end{tabular}

Table 5: the real valued of the AIC, and HQIC

\begin{tabular}{|c|c|c|}
\hline & AIC & HQIC \\
\hline Gaussian copula & 1070 & 618 \\
\hline Student's t copula & 1071 & 617 \\
\hline
\end{tabular}

Table 6: The MAPE of hourly demand prediction using Gaussian copula

\begin{tabular}{|c|c|c|c|}
\hline \multirow{2}{*}{ Number of Gen. data sets } & \multicolumn{3}{|c|}{ Number of selected days } \\
\cline { 2 - 4 } & $\mathbf{1 5}$ & $\mathbf{1 0}$ & $\mathbf{5}$ \\
\hline $1 E 2$ & 1.68 & 1.28 & 1.15 \\
\hline $1 E 3$ & 1.31 & 1.19 & 1.09 \\
\hline
\end{tabular}

\section{Simulation}

\subsection{Short-term load prediction}

To verify the proposed method of the STLF, 30 days in April 2018 was investigated due to high changes in temperature seasonality, and for example, 22th day in this case as a working day was explained for hourly load forecasting. To calculate the nonlinear relationship between the load consumption at different times in a day and to model the power consumption, which was used copula functions, demand profiles of the 20 days same as 22 th of April 2018, were selected. Fig. 10 demonstrates the load profiles of the 20 selected days; as it can be seen that the load profiles of the 20 selected days are usually similar, and only electric power consumption level is deferent on various days. In the following, the next hour demand is forecasted using Gaussian, and Student's t copula, and the results are compared.

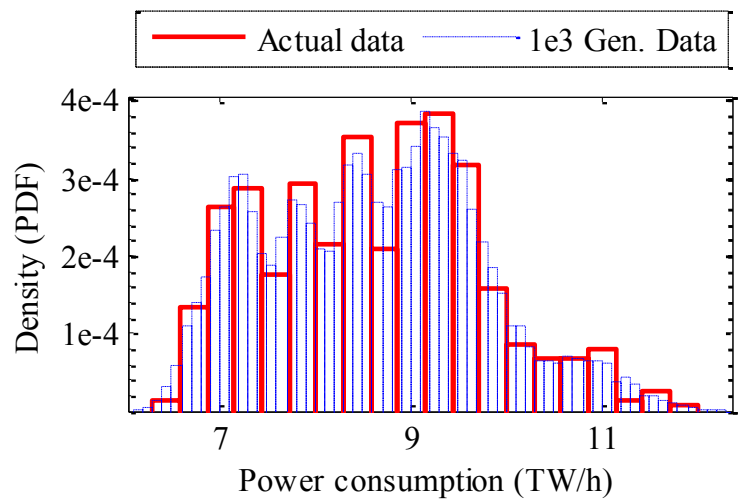

Fig. 11: PDF of hourly demand for 20 days and 1000 data sets

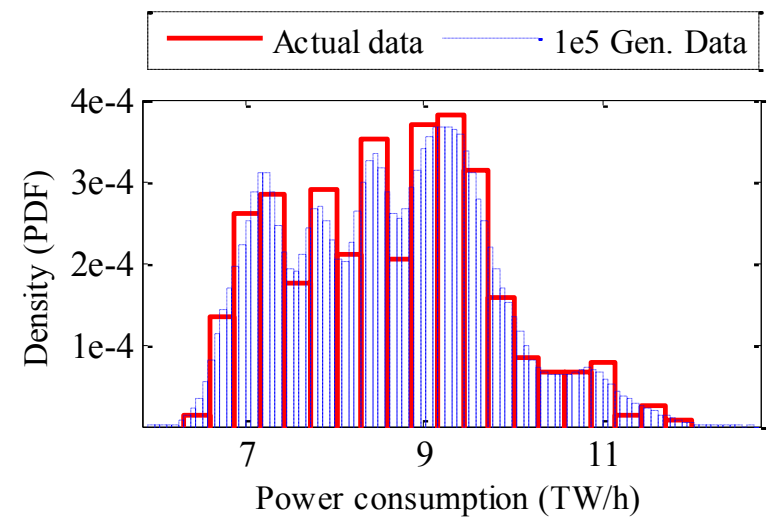

Fig. 12: PDF of hourly demand for 20 days and a million data sets that were generated using Gaussian copula

\subsubsection{Load prediction for the next hour using GC}

Based on the proposed method, the 20 actual data were considered for each hour of the selected days (14). According to the generated vectors, $\mathrm{mf}$, the Kendall's rank correlation $(\tau)$ among 24 variables were obtained (7), and the Parameters of the Gaussian and Student's t copula functions are estimated by means of an approximation to Kendall's rank correlation. The coefficient matrix, Rho, of the GC for 24 variables was illustrated in table. 2. As previously mentioned, the jth hour demand is more dependence with the load consumption in the ith hour, while $(i<j)$. Information about the ith hour demand was used to predict the load consumption in the jth hour. For example, the load consumption in the 8th hour, $\mathrm{m} 8$, is more dependence with the load consumption in the 3rd hour (m3), so the 3rd hour demand was used to predict the 8th hour demand. According to the proposed algorithm at the first step for STLF, using appropriate CDF (usually normal CDF) to transform actual variables to $U_{w} \in[0,1], w=$ 
$1,2, \ldots 24$, and than 1000 data sets were generated which each data sets includes 24 data; based on Rho, (table. 2).

In the following, appropriate ICDF which was obtained from the first stage is applied to transform 1000 data sets with a uniform distribution to the simulated variables which are the same characteristic (PDF) as well as the actual variables. The red curve in Fig. 11 illustrates the probability density function (PDF) of the hourly demand for the 20 selected days, and the blue curve shows the PDF of 1000 data sets, which were generated using GC. In addition, Fig. 12 demonstrates the PDF of the hourly 20 selected days demand, and 1E5 data sets, which were produced using Gaussian (Normal) copula. Based on the results (Fig. 11-12), the PDF of the produced data using GC and the actual historical data of the hourly load consumption from 20 selected days are identical.

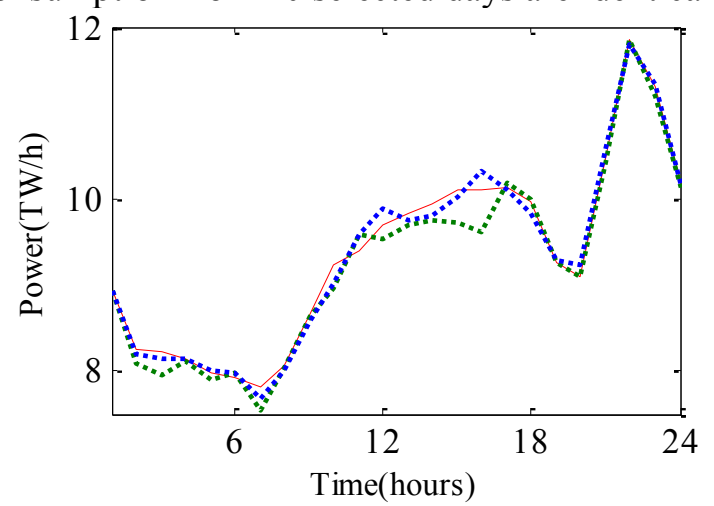

Fig. 13: Actual load and next-hour demand prediction using GC in the $22^{\text {th }}$ of April 2018

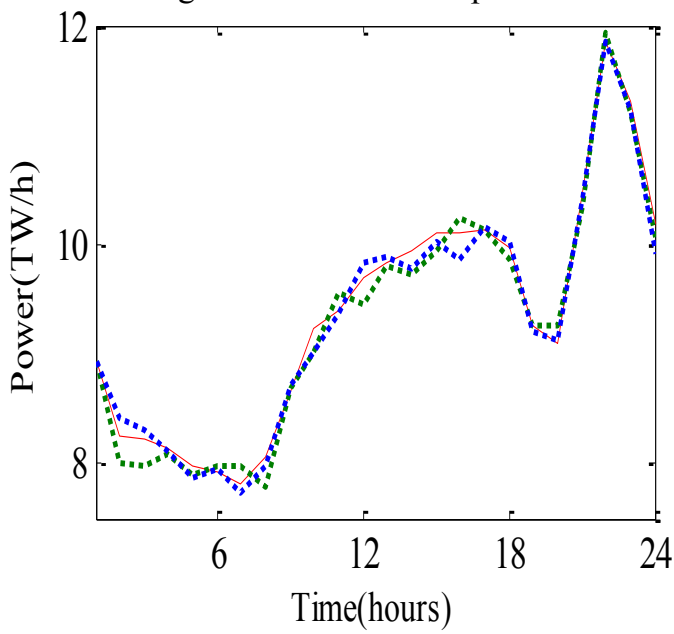

Fig. 14: Actual load and next-hour demand prediction using Student's t copula in the $22^{\text {th }}$ of April 2018

Table 3 shows the general form of the generated data sets which were produced, where $\mathrm{k}$ is the number of data sets. Considering the ith hour demand to predict the load consumption in the $\mathrm{jth}$ hour while $\beta_{\mathrm{j}}^{\mathrm{i}}$ is the greatest rank correlation in the $j$ th row when $(i<j)$ (Fig.3). Among generated data sets in the mi column (table 3), Load $_{\mathrm{i}}^{\mathrm{k}}$ was chosen because the ith hour demand is closer to it. Therefore, the expected demand in the jth hour is equal to $\operatorname{Load}_{j}^{k}$. To verify the proposed method 30 days were investigated, April 2018, to predict the next hour demand. In this case, according to the proposed method maximum, minimum, and average of MAPE is shown in table 4. As can be seen from this table, by using the Gaussian copula method, the difference between 1E5 maximum and minimum value is minor than this value for 1E3. Similarly, by using the student's $t$ copula, the difference between Max-MAPE and MinMAPE is lower in the 1E5 generation data. To predict the 8th hour in the 22th day in this case according to the coefficient matrix (table 2) the load consumption in the 8th hour is more dependence with the 3rd hour demand $\left(\beta_{8}^{3}=0.88\right)$. so in the third column of the generated data sets real valued $\mathrm{k} 1$ was chosen due to the smallest difference between the $\operatorname{Load}_{3}^{k}$ and the 3rd hour demand, where $\mathrm{k} 1 \epsilon \mathrm{k}, \mathrm{k}=\{1, \ldots, 1000\}$ $(\mathrm{k} 1=491)$. The expected demand in the 8th hour is equal to $\operatorname{Load}_{8}^{k_{1}}$. The red curve in Fig. 13 illustrates the actual load consumption profile; the blue and green curves show the forecasted next-hour demand with 1E5, and 1E3 generated data sets, respectively. As is clear from the simulation results prediction accuracy was increased due to increase the number of generated data sets $(\mathrm{k})$. If the number of selected days is decreased closer to considered day, the MAPE is reduced because of more intervals due to some of geography and social changes (table 6). This is because of data generated method. When the data fed to the GC or GMM functions is closer to the considered day, the data generator functions can produce data sets with a minor errors. Choosing 4 or 5 days within 15 to 25 days ago, next-hour demand was accurately forecasted based on the results. Therefore, the number and usage time of meters in distribution system is reduced using proposed methods.

\subsubsection{Load prediction for the next hour using Student's t copula}

In this section, electric power consumption was predicted and modeled using Student's t copula. In section III, the AIC, and HQIC criteria for selecting the best type of copula functions were expressed. It can be seen in table 5 that the value of AIC, and HQIC criteria based on the actual value of the 24 variables for Gaussian and Student's t copula are almost equal. Thus, it is expected that the results of using t copula is close to the results of using GC. Note that the $\mathrm{GC}$ is a special case of the $\mathrm{t}$ copula, where GC is the Student's t copula with degree of freedom 


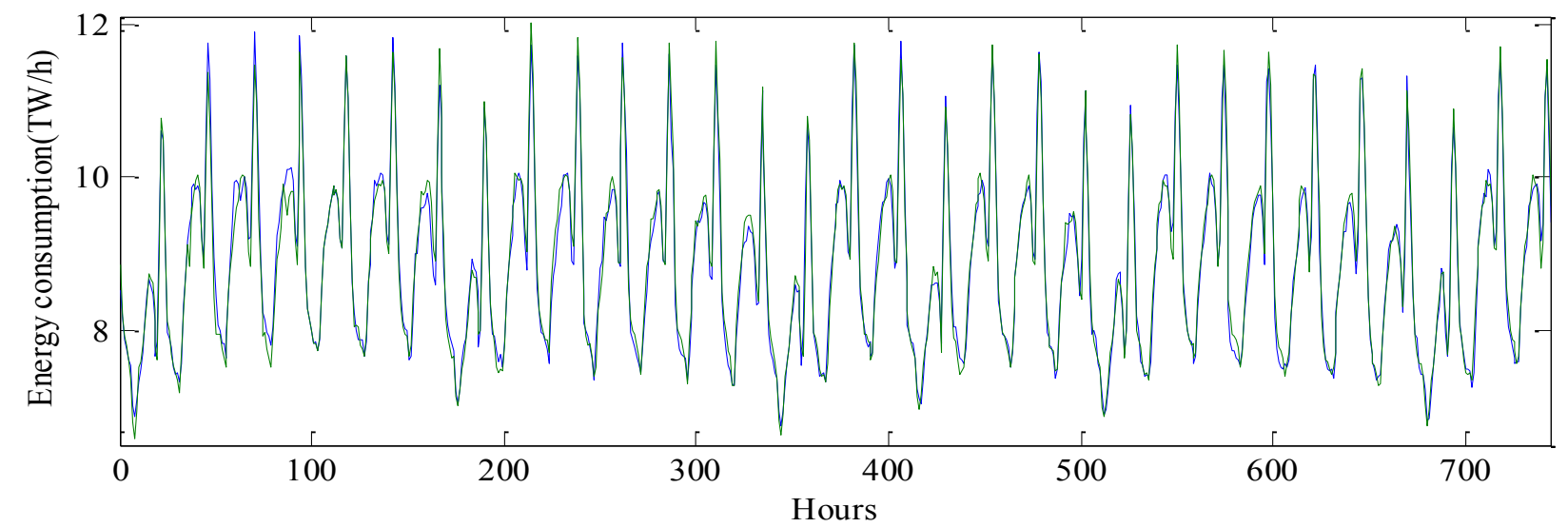

Fig. 15: Actual load (blue), next-day load prediction of the proposed method using GC with weekends and holidays of April 2018

to tend to infinity. STLF algorithm using GC and Student's t copula are similar. However, to determine the parameters of the Student's t copula degree of freedom, $\mathrm{v}$, is calculated as well the coefficient matrix, Rho. For STLF (next hour) in 22 April 2018 using Student's t copula, coefficient matrix and degree of freedom were calculated by Kendall's Rank correlation $(\tau)$, which $\mathrm{v}$ is equal to $3.5 \mathrm{E} 7$. The value of $v$ shows that the Student's t copula tends toward the GC. The blue and green curves with 1E5, and 1E3 generated data in Fig. 14 show the next hour forecasted load in 22th of April 2018, respectively. In addition, maximum, minimum, and average MAPE of next hour demand prediction for April 2018 are shown in table. 4. The results of the STLF using Student's $t$ and GC are almost identical. Using Student's $t$ copula to predict the next hour consumption by increasing the number of generated data sets, $\mathrm{k}$, prediction accuracy increases as well as using GC.

\subsubsection{Load forecasting for the next day}

To evaluate the proposed method of the hourly next day demand prediction, hourly demand of November 2018 with holidays and weekends were explored and the results were shown in Fig. 15, where blue line illustrates the actual hourly demand and green line shows the hourly next day demand prediction. In this case, the maximum, minimum, and average MAPE respectively are $0.08,2.56$, and 1.56 percentages, which are acceptable. For example based on the available historical data to date 29th of November 2018, the hourly demand in the 11/30/2018 was forecasted. According to the proposed algorithm (Fig. 7); at first several similar consecutive days were selected based on the type of 11/30/2018.

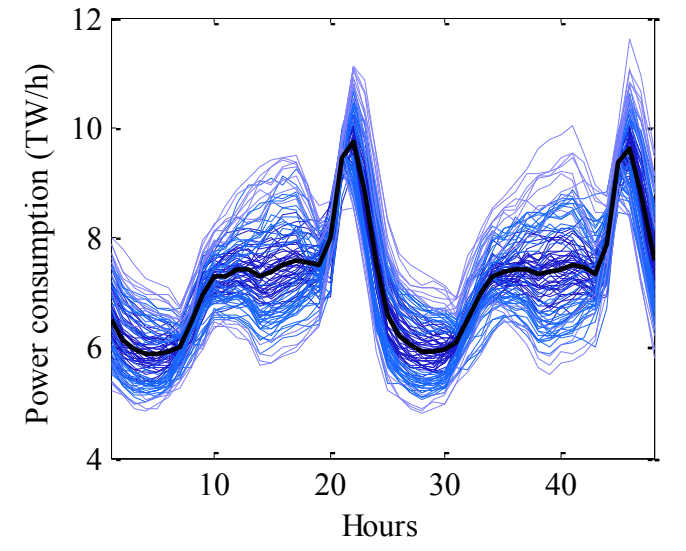

Fig. 16: 100 data sets were generated using GC

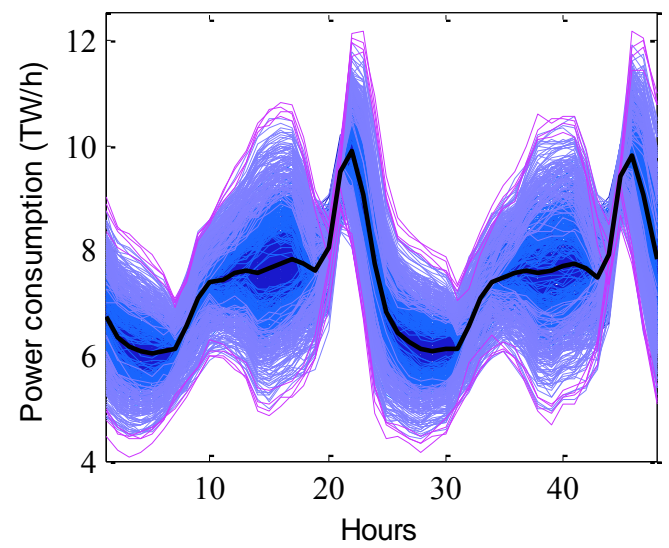

Fig. 17: 1000 data sets were generated using GC

It can be seen in table. 7 to forecast hourly load consumption from 3 to 30 similar consecutive days have been selected. For each of the various states from 1E2 to 3E5 data strings were generated using GC that each data set includes 48 data. For example Fig. 16, 17 show 1E2, and 1E3 data sets using GC, while 5 consecutive similar days had been chosen. In order to predict hourly demand in this case, after the following step by step the proposed algorithm (Fig. 7) the value of MAPE was calculated, according to the hourly load demand in 11/30/2018. Based on the 
results (Table 7), if the number of selected similar two days were increased, the MAPE was high because of more intervals due to some of geography and social changes.

Table 7: The MAPE of the predicted load consumption on Monday 1372/3/31 for various several days

\begin{tabular}{|c|c|c|c|c|c|c|c|c|c|c|c|c|}
\hline \multirow{2}{*}{$\begin{array}{c}\text { The } \\
\text { number of } \\
\text { Gen. data } \\
\text { sets }\end{array}$} & \multicolumn{12}{|c|}{ Number of selected days } \\
\hline & 3 & 4 & 5 & 6 & 7 & 8 & 9 & 10 & 15 & 20 & 25 & 30 \\
\hline $1 E 2$ & 1.74 & 1.59 & 1.51 & 2.05 & 1.56 & 2.13 & 2.22 & 5.3 & 3.74 & 5.21 & 3.24 & 2.71 \\
\hline $1 E 3$ & 1.69 & 1.55 & 1.5 & 1.81 & 1.98 & 2.53 & 4.99 & 6.08 & 4.98 & 5.5 & 5.19 & 3.95 \\
\hline $2 E 3$ & 93 & 1.54 & 1.44 & 1.85 & 1.9 & 2.02 & 5.23 & 2.95 & 5.41 & 4.36 & 5.97 & 6.93 \\
\hline $5 E 3$ & 1.9 & 1.55 & 1.55 & 1.55 & 1.97 & 2.2 & 7.84 & 2.67 & 5.5 & 6.05 & 4.73 & 5.84 \\
\hline $1 E 4$ & .68 & 1.56 & 1.49 & 2.23 & 2.08 & 2.75 & 5.22 & 3.61 & 7.76 & 2.87 & 3.25 & 4.31 \\
\hline $2 E 4$ & 1.67 & 1.58 & 1.53 & 1.91 & 2.2 & 2.41 & 4.61 & 3.61 & 4.64 & 5.16 & 4.62 & 4.81 \\
\hline $3 E 4$ & 1.67 & 1.56 & 1.64 & 2.6 & 2.01 & 2.11 & 5.04 & 3.68 & 6.32 & 7.65 & 6.81 & 6.66 \\
\hline $1 E 5$ & 1.68 & 1.56 & 1.65 & 2.1 & 1.96 & 1.82 & 3.82 & 5.11 & 6.39 & 4.04 & 8.32 & 6.53 \\
\hline $2 E 5$ & 1.67 & 1.59 & 1.64 & 2.58 & 1.89 & 2.16 & 5.01 & 5.66 & 6.09 & 3.92 & 9.06 & 7.66 \\
\hline $3 E 5$ & 1.68 & 158 & 1.58 & .6 & 2 & 2.3 & 2.6 & 6.2 & 4.5 & 2.01 & 7.2 & 3.81 \\
\hline
\end{tabular}

In addition, according to the results $1.2 \%$ is the appropriate amount for $\varepsilon 0$. Furthermore adding hourly temperature of the day to the load forecasting model the MAPE value increases between 0.05 to 0.2 percent. Therefore, to increase the prediction accuracy using two consecutive days model (Fig. 6) and selecting 4 to 5 recently similar days were proposed to forecast the next-day demand because of considering changing temperature due to the high inertia of temperature and load. In the table 8 , it is compared the Ave. MAPE (\%) values for the last four years. It can be seen that the MAPE(\%) of the proposed is in Next-hour, next day and next month has the best Ave. MAPE (\%) values than the ANN technique, MLP algorithm and hybrid intelligent approach. Therefore, the proposed method gives a better forecast error.

Table 8: Ave. MAPE (\%) values of the proposed method and ANN technique presented in [1-4] for the last four years of the available data

\begin{tabular}{|c|c|c|c|}
\hline & $\begin{array}{c}\text { Next- } \\
\text { hour }\end{array}$ & $\begin{array}{c}\text { Next- } \\
\text { day }\end{array}$ & $\begin{array}{c}\text { Next- } \\
\text { month }\end{array}$ \\
\hline Proposed method & 0.99 & 1.58 & 0.85 \\
\hline ANN technique & 1.14 & 2.11 & 1.85 \\
\hline MLP algorithm & 1.43 & 1.62 & 2.27 \\
\hline $\begin{array}{c}\text { Hybrid Intelligent } \\
\text { Approach }\end{array}$ & 1.23 & 2.13 & 1.89 \\
\hline
\end{tabular}

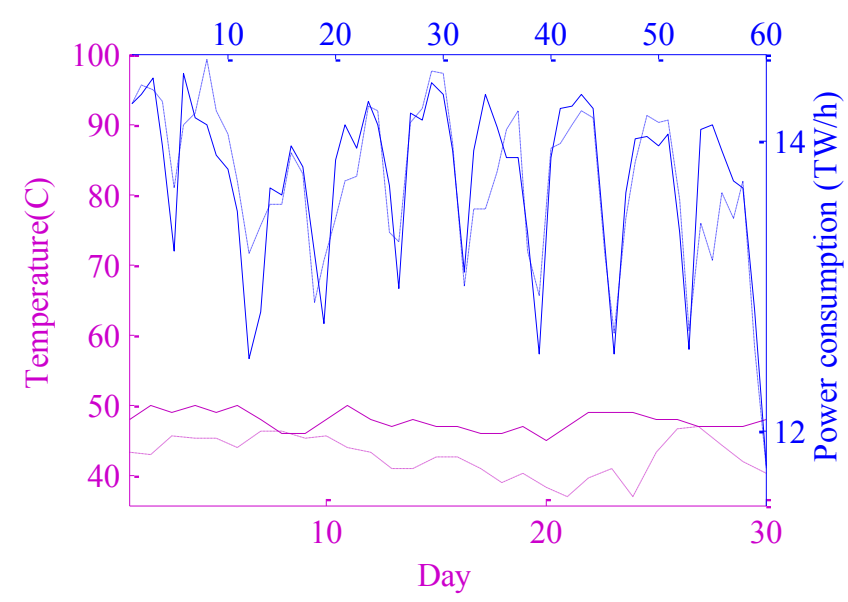

Fig. 18: the closest data set of generated data (dot line) to the actual data (solid line) was produced using Gaussian copula

\subsection{Peak load forecasting of the next month}

To evaluate the proposed method to predict the next month peak demand using GC the daily peak demand was forecasted in October 2018. The case study is 5series data from April 2018 to September 2018 in accordance with the general form (Fig. 9) was selected to determine the characteristic of the GC. The GC is known as Elliptical copula. The mdimensional GC is presented as followings:

$C^{m}\left(u_{1}, u_{2}, \ldots, u_{m} ; R h o\right)$

$=\varphi_{m}\left(\varphi^{-1}\left(u_{1}\right), \varphi^{-1}\left(u_{2}\right), \ldots, \varphi^{-1}\left(u_{m}\right) ; \boldsymbol{R} \boldsymbol{h} \boldsymbol{o}\right)$

Where $\varphi^{-1}($.$) is the inverse function of the standard$ normal distribution $\varphi($.$) . Additionally, \varphi_{m}(. ;$ Rho) is the $\mathrm{m}$-dimensional standard distribution function with mean vector and covariance matrix similar to the, Rho.

To simulate multiple dependent variables using the copula method each of the following should be clear:

- The copula method type and its parameters.

- The variables and correlations rank.

- Distribution parameters for each variable.

According to the characteristic of the GC 1000 series 90 pieces of data were generated and finally, the best data set was selected based on Eq. 21. Fig. 18 shows the closest data set to the actual data, which was obtained by, suggested algorithm. Pink solid and dot line in Fig. 18 represents the maximum daily temperature in September 2018 and the first 30 data in selected data set, respectively; Blue solid line shows the maximum daily demand consumption during September and October, while the blue dots represent the generated data using GC. As stated previously, the 30 end generated data in each data set represents the maximum daily load consumption for the next month, October 2018, which were 
forecasted. In this case study, MAPE of peak demand in October 2018 is equal to 1.69 percentages, while the average MAPE of the maximum daily consumption is 0.8 percentages.

\section{Conclusion}

The availability of data is a necessary aspect of the load prediction by the statistical and evolutionary methods, which was rarely recorded in distribution system due to the vastness of it. In this paper, a new method has been suggested based on copula in shortterm, and (mid \long)-term period to forecast the load consumption in distribution system. Samples are taken from data collected from residential units. This real data is fed to a GC or GMM function to generate new data. It is presented that appropriated results were achieved by the proposed method due to insufficient historical data; therefore the number and usage time of meters is reduced using presented method. Simulations illustrated that the proposed method has a low average MAPE compared with the other load forecasting techniques. Finally, the proposed algorithm using copula was strongly recommended that should be considered by utility companies to forecast demand for the efficient management in distribution systems.

\section{Reference}

[1] P. Chege, "Probability and Statistics," 2010.

[2] F. Li, X. Wang, and Y. Li, "Effects of singular value spectrum on the performance of echo state network," Neurocomputing, vol. 358, pp. 414-423, 2019.

[3] M. Ghaderi, H. Javadikia, L. Naderloo, M. Mostafaei, and H. Rabbani, "Analysis of noise pollution emitted by stationary MF285 tractor using different mixtures of biodiesel, bioethanol, and diesel through artificial intelligence," Environmental Science and Pollution Research, vol. 26, no. 21, pp. 2168221692, 2019.

[4] M. Askari and F. Keynia, "Mid-term electricity load forecasting by a new composite method based on optimal learning MLP algorithm," IET Generation, Transmission \& Distribution, vol. 14, no. 5, pp. 845-852, 2020.

[5] S. Anbazhagan and K. Vaidehi, "ShortTerm Load Forecasting Using Wavelet Denoising Signal Processing Techniques," in Data Engineering and Communication Technology: Springer, 2020, pp. 697-705.
[6] X. Tang, Y. Dai, T. Wang, and Y. Chen, "Short-term power load forecasting based on multi-layer bidirectional recurrent neural network," IET Generation, Transmission \& Distribution, vol. 13, no. 17, pp. 3847-3854, 2019.

[7] H. R. Alirezaei, A. Salami, and M. Mohammadinodoushan, "A study of hybrid data selection method for a wavelet SVR mid-term load forecasting model," Neural Computing and Applications, pp. 1-11, 2019.

[8] G. Černe, D. Dovžan, and I. Škrjanc, "Short-term load forecasting by separating daily profiles and using a single fuzzy model across the entire domain," IEEE Transactions on Industrial Electronics, vol. 65, no. 9, pp. 74067415, 2018.

[9] A. Tarsitano and I. L. Amerise, "Shortterm load forecasting using a two-stage sarimax model," Energy, vol. 133, pp. 108-114, 2017.

[10] D. J. Bartholomew, "Time series analysis forecasting and control," Journal of the Operational Research Society, vol. 22, no. 2, pp. 199-201, 1971.

[11] Y. Liang, D. Niu, and W.-C. Hong, "Short term load forecasting based on feature extraction and improved general regression neural network model," Energy, vol. 166, pp. 653-663, 2019.

[12] J. Luo, T. Hong, and S.-C. Fang, "Robust regression models for load forecasting," IEEE Transactions on Smart Grid, vol. 10, no. 5, pp. 5397-5404, 2018.

[13] J. F. Rendon-Sanchez and L. M. de Menezes, "Structural combination of seasonal exponential smoothing forecasts applied to load forecasting," European Journal of Operational Research, vol. 275, no. 3, pp. 916-924, 2019.

[14] R. E. Abdel-Aal, "Short-term hourly load forecasting using abductive networks," IEEE Transactions on Power Systems, vol. 19, no. 1, pp. 164-173, 2004.

[15] G. Dudek, "Neural networks for patternbased short-term load forecasting: A comparative study," Neurocomputing, vol. 205, pp. 64-74, 2016.

[16] R. Hu, S. Wen, Z. Zeng, and T. Huang, "A short-term power load forecasting model based on the generalized regression neural network with decreasing step fruit fly 
optimization algorithm," Neurocomputing, vol. 221, pp. 24-31, 2017.

[17] N. Vafamand, M. M. Arefi, and A. Khayatian, "Nonlinear system identification based on Takagi-Sugeno fuzzy modeling and unscented Kalman filter," ISA transactions, vol. 74, pp. 134-143, 2018.

[18] M. Torabi, S. Hashemi, M. R. Saybani, S. Shamshirband, and A. Mosavi, "A Hybrid clustering and classification technique for forecasting short-term energy consumption," Environmental Progress \& Sustainable Energy, vol. 38, no. 1, pp. 66-76, 2019.

[19] G. T. Ribeiro, V. C. Mariani, and L. dos Santos Coelho, "Enhanced ensemble structures using wavelet neural networks applied to shortterm load forecasting," Engineering Applications of Artificial Intelligence, vol. 82, pp. 272-281, 2019.

[20] M. Rana and I. Koprinska, "Forecasting electricity load with advanced wavelet neural networks," Neurocomputing, vol. 182, pp. 118132, 2016.

[21] R. B. Nelsen, An introduction to copulas. Springer Science \& Business Media, 2007.

[22] S. Obzigailov, "Modeling and forecasting demand for natural gas of retail consumers," Master's thesis, 2011.

[23] J. Rank, Copulas: From theory to application in finance. Bloomberg Press, 2007.

[24] X. Li, W. Zhang, and L. He, "A Novel Nonparametric Estimation for Conditional Copula Functions Based on Bayes Theorem," IEEE Access, vol. 7, pp. 186182-186192, 2019.
[25] C. Pan, C. Wang, Z. Zhao, J. Wang, and Z. Bie, "A Copula Function Based Monte Carlo Simulation Method of Multivariate Wind Speed and PV Power Spatio-Temporal Series," Energy Procedia, vol. 159, pp. 213-218, 2019.

[26] E. W. Frees and E. A. Valdez, "Understanding relationships using copulas," North American actuarial journal, vol. 2, no. 1, pp. 1-25, 1998.

[27] Z. Wang, W. Wang, C. Liu, Z. Wang, and Y. Hou, "Probabilistic forecast for multiple wind farms based on regular vine copulas," IEEE Transactions on Power Systems, vol. 33, no. 1, pp. 578-589, 2017.

[28] D. X. Li, "On default correlation: A copula function approach," The Journal of Fixed Income, vol. 9, no. 4, pp. 43-54, 2000.

[29] D. Vose, T. Koupeev, M. Van Hauwermeiren, W. Smet, and S. van den Bossche, "Help File for ModelRisk Version 5 Vose Software (2007)," ed.

[30] S. Yilmaz, J. Chambers, and M. K. Patel, "Comparison of clustering approaches for domestic electricity load profile characterisation-Implications for demand side management," Energy, vol. 180, pp. 665-677, 2019.

[31] L. Gan, X. Chen, K. Yu, J. Zheng, and W. Du, "A Probabilistic Evaluation Method of Household EVs Dispatching Potential Considering Users Multiple Travel Needs," IEEE Transactions on Industry Applications, 2020.

\section{Creative Commons Attribution License 4.0 (Attribution 4.0 International, CC BY 4.0)}

This article is published under the terms of the Creative Commons Attribution License 4.0

https://creativecommons.org/licenses/by/4.0/deed.en US 